\title{
Financial Risk and Unemployment
}

\author{
Zvi Eckstein
}

Tel Aviv University and The Interdisciplinary Center Herzliya

\section{Ofer Setty}

Tel Aviv University

David Weiss

Tel Aviv University

\section{PRELIMINARY DRAFT: February 2014}

\begin{abstract}
There is a strong correlation between the corporate interest rate spread and the unemployment rate. We make two contributions to the literature based on this observation. First, we model the mechanisms by which these financial conditions can affect unemployment in a DMP model with capital. Second, we quantify these mechanisms, disciplining our model with US data. Financial conditions affect unemployment in four ways. First, high interest rates lower profits. Second, higher interest rates make vacancy posting more costly. Third, higher default rates lower the expected future profits of firm owners. Finally, default can lead directly to a separation between the worker and firm. We quantify these channels following various strategies outlined in the literature. Preliminary results suggest the model is able to produce quantitatively significant fluctuations under all calibration strategies.
\end{abstract}




\section{Introduction}

There is a strong correlation between the interest rate spread, as defined by the difference in yields on BAA grade corporate bonds and US Treasury bonds, and the unemployment rate. This correlation is similar in magnitude to that of unemployment and productivity, the most common force used by economists to study unemployment fluctuations. Despite this strong empirical connection, the search based unemployment literature has not analyzed how the interest rate spread affects unemployment. We develop an extension of the Diamond-Mortensen-Pissaridies model, as in Diamond (1982), Mortensen (1982), and Pissarides (1985) (DMP), to allow us to quantify various mechanisms through which financial conditions, as captured by the interest rate spread, may affect unemployment.

We are not trying to solve the 'Shimer Puzzle', introduced in Shimer (2005) (henceforth Shimer), of whether productivity shocks can explain labor market fluctuations in the DMP model. Rather, we are introducing a new set of shocks, the interest rate \& spread, and their associated mechanisms. We then need to show that our approach is quantitatively useful in studying unemployment. To do so, we follow the outline of the 'Shimer Puzzle' literature in measuring the importance of shocks in a DMP setting.

In Figure 1, we show time series data of the interest rate spread and unemployment in the US from 1970 to 2012. The correlation between these series is 0.49 . We cannot reject the hypothesis that the interest rate spread Granger-causes unemployment fluctuations.1 We thus take the corporate interest rate to be an exogenous shock. Additionally the real BAA interest rate has a correlation with unemployment of 0.32 , the importance of which is discussed below. As a point of comparison, the correlation between productivity and unemployment as reported by Hagedorn and Manovskii (2008), henceforth HM, is -.30.

Due to the spread rising in recessions, borrowing costs to firms rise in recessions despite lower Federal Funds Rates. We make two contributions to the literature based on the observation that the interest rate spread and the interest rate to firms (BAA) are countercyclical with a strong correlation with unemployment. First, we add capital to the DMP model and explain the mechanisms by which financial conditions, assumed to be exogenous, can affect unemployment. Second, we quantify these mechanisms, disciplining our model with US data.

We now discuss four mechanisms by which the interest rate spread, and implied rises in actual interest rates, can generate unemployment in the context of the standard DMP model. The first

\footnotetext{
${ }^{1}$ For the Granger causality test, we use a lag of 2 quarters.
} 


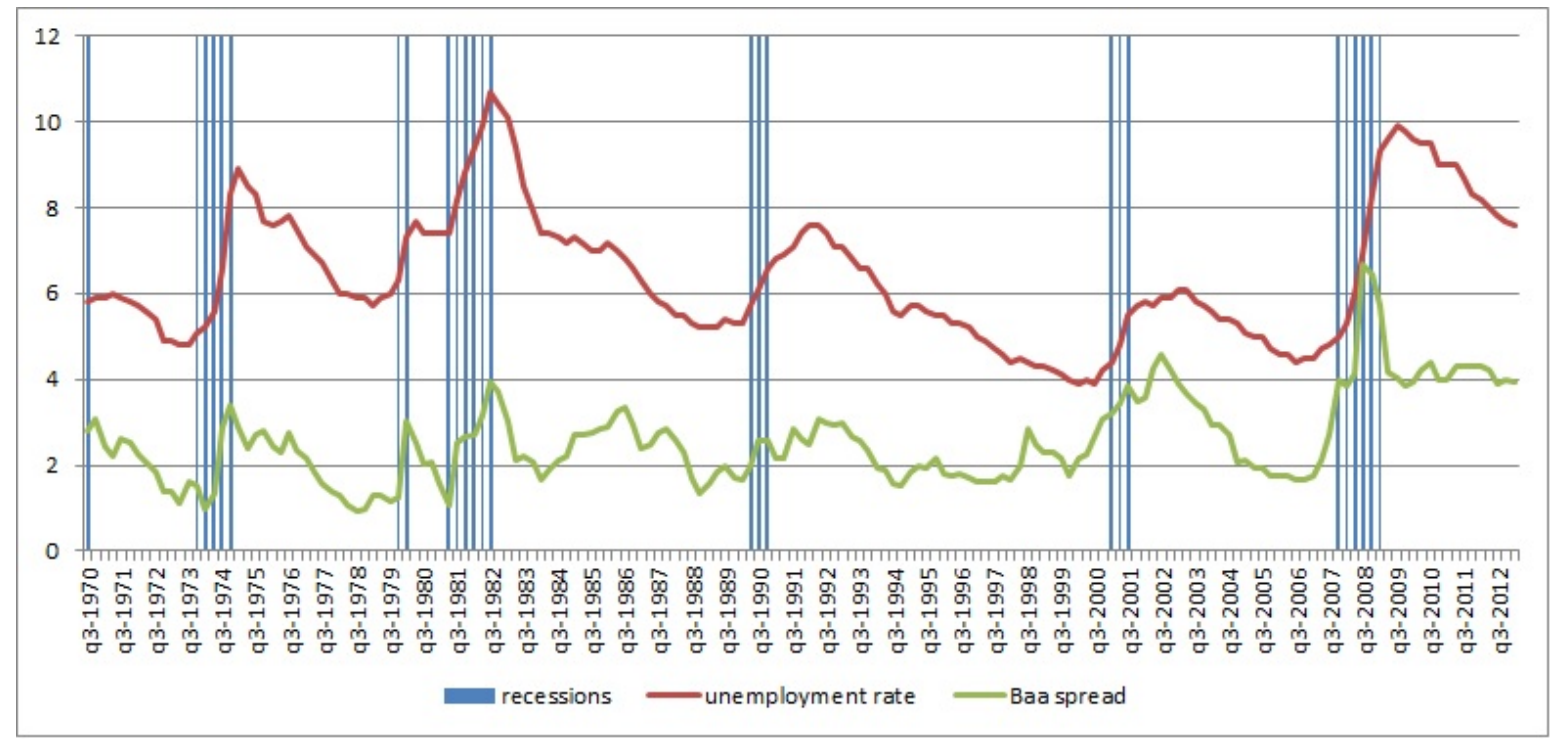

Figure 1: Interest Rate Spread and Unemployment

channel is what we call the direct profit channel. This is the notion that, if interest rates rise for firms, then profits per worker will be reduced, as the capital the worker uses becomes more expensive. Thus the incentive to post vacancies declines, and unemployment rises. The second we call the direct vacancy channel. If firms need to have some working capital in order to post a vacancy, such as a computer ready for the worker, then a rise in interest rates directly increases the costs of vacancies leading to higher unemployment. The third channel is the indirect bankruptcy channel. Bankruptcy results in the owners of the firm losing their status as the claimants on any future profits. As bankruptcy rates increase, the owners expect fewer future profits, and thus post fewer vacancies. Unemployment rises. The final channel is the direct bankruptcy channel, or the simple notion that bankruptcies often result in a contemporaneous rise in separations between workers and firms, and thus a rise in unemployment. Notice that the first two channels rely simply on the interest rate for firms rising, while the second two mechanisms infer rising firm default rates from the interest rate spread.

We begin by writing the partial model that only includes the first two mechanisms, that is the direct profit channel and the direct vacancy channel. The model is a standard DMP model, with a fixed amount of capital per worker ${ }^{2}$ While we include the direct profit channel, we focus on quantifying the direct vacancy channel. We calibrate the model to the US data in two different

\footnotetext{
${ }^{2}$ We perform a robustness exercise on the assumption of a fixed capital per worker ratio and find it to not be an important assumption.
} 
ways. First we follow the calibration strategy in HM, but do not use their parameter values. The model is able to produce quantitatively significant business cycle fluctuations, matching about $60 \%$ of the model's empirical counterparts. Our value for the flow utility of leasure is $58 \%$ of the average wage. This number is higher than that in Shimer, and lower than that of HM. Our value of the worker's bargaining weight is 0.52 , which is similarly between those used by HM and Shimer. Our preliminary results including the direct profit channel can explain virtually all of the observed business cycle volatility in the US data.

We then use the numbers reported in Shimer as a calibration. We find very similar results as in the HM calibration. $3^{3}$ The reason for this is that much of the driving force for the model comes from the direct vacancy channel. The mechanism used to drive unemployment in both HM and Shimer specification of the DMP model is the analog of the direct profit channel- an adverse productivity shock decreases future match surplus. Preliminary results including the direct profit mechanism show that it adds noticeable quantitative power to the Shimer calibration case, and, unsurprisingly, even stronger results under the HM calibration strategy. It should be noted that no business cycle properties of the US data are targeted in any of the calibration strategies discussed here or in the previous paragraph, and yet the model is able to match the properties of the data quite well.

We then expand the model to include the second two channels. We are interested in the default rate of firms in the economy. This can be inferred from the interest rate spread the probability of firms entering default. That is, the spread implies that financial intermediaries expect a certain level of risk, where the risk is both that of default and low recovery rates from firms in default. The assumption that the recovery rate is zero implies the lowest possible inferred default rate, which is a conservative viewpoint given our mechanisms. Next, since it is unreasonable to assume that all of the spread is due to increased risk of default, we add a coefficient to the inferred default risk $\eta_{1}$.

Similarly, not all defaulting firms will end up separating from their workers. Some firms, such as American Airlines after their 2010 bankruptcy, continue operating even after a bankruptcy episode despite their equity owners losing all claims to profits. We capture this fact by adding another parameter, the fraction of matches that are ended in a bankruptcy experience, $\eta_{2}$.

We pick these two parameters jointly in order to match the correlation of the interest rate spread and vacancies, and the correlation of the spread and separations in the US time series data. We do not yet have our results for this section.

Most of the DMP literature on unemployment focuses on the effects of productivity shocks.

\footnotetext{
${ }^{3}$ In order to maintain comparability of our results, we use the matching function in HM throughout the paper, regardless of the fact that Shimer uses a somewhat different matching function.
} 
Shimer launched a literature on if/how the DMP model could be made consistent with the empirical realities of unemployment volatility given low volatility in productivity. HM offer one solution, depending on a high value of unemployment. Petrosky-Nadeau and Zhang (2013) estimate the DMP model in order to be consistent with the US time series, including the Great Depression, and find that it can also explain the Great Recession. They use Hall and Milgrom (2008) style wage setting, and a congestion externality in order to create asymmetric affects of recessions and booms. Numerous other papers take different avenues to address the 'Shimer Puzzle', or how relatively small productivity shocks can drive large unemployment and vacancy volatility. We take a different approach from this research agenda in adding financial conditions to the DMP model, rather than examining productivity shocks, and show that the model is robustly able to explain the US business cycle data.

We are not the first to introduce financing to the DMP model. Wasmer and Weil (2004) include financial conditions in a DMP model by adding a search dimension to locating capital. Our study quantifies different mechanisms, and is thus complementary to their paper. Hall (2014) takes an interesting approach to the DMP model in assuming the discount rate is stochastic. This approach is innovate in that it connects the DMP literature to the finance literature that uses stochastic discount rates in order to explain high stock volatility. Yashiv (2013) studies the interaction between frictions in the labor and capital markets. He shows that investment decisions and hiring decisions are intimately related, and that it is necessary to model them jointly in order to explain the US data. Christiano, Eichenbaum, and Trabandt (2013) have an ambitious agenda of incorporating a New Keynesian model with elements of a search model of the labor market in order to explain the Great Recession. In their paper, the interest rate affects unemployment through the standard New Keynesian channel; lower interest rates increase demand for final goods and services. For us, lower interest rates increase profits for the firm, and lower vacancy costs. We thus study different channels through which financial conditions affect unemployment, and do so in different modeling frameworks.

Mitman and Rabinovich (2013) and Hagedorn, Karahan, Manovskii, and Mitman (2013), show how extensions in unemployment benefits can explain persistence in high unemployment rates since the early 1990s and especially in the Great Recession. They do not explain the initial rise in unemployment. We complement their findings by studying the effects of financial conditions on the initial rise in unemployment in the Great Recession by simulating our model given the realized interest rates/interest rate spread during this time period. Note that these results are not yet included. 
We proceed as follows. In Section 2 we describe the partial model. Section 3 describes the value functions, solution of the model, and the full model with the interest rate spread mechanisms. Section 4 describes the economic mechanisms in the model in full detail. We discuss the calibration strategy and exercise in Section 5. We conclude in Section 7 .

\section{The Model}

We take the standard DMP model, as in HM and Shimer. We replace shocks to productivity with shocks to interest rates. We describe the model in full detail in this section. We start by describing the partial model.

\subsection{Workers and Firms}

There is a measure one of infinitely lived, risk neutral workers and a continuum of infinitely lived firms. Workers maximize their expected lifetime utility:

$$
\mathbb{E} \sum_{t=0}^{\infty} \beta^{t} y_{t},
$$

where $y_{t}$ represents the workers' income in a given time period, and $\beta$ is the discount factor.

Firms produce using workers and capital. We assume that capital per worker is fixed and that output is linear in the number of workers, making production a Lenotief function. Output is thus given by

$$
Q(L, K)=\min \left\{p L, \frac{K}{\phi}\right\}
$$

where $p$ is labor productivity and $\phi$ controls the capital per effective worker, $k$. However, given that we study deviations in the interest rate from trend, this is analogous to a model in which the firm decides capital stock per worker based on interest rate trends, and then cannot adjust in response to fluctuations. We perform a robustness check on the production function by simply eliminating this channel the robustness section. Capital is elastically supplied by an exogenous financial market. Suppressing the fixed capital component of production gives us production as a function of labor:

$$
q(L)=p L
$$


where $K$ is implied to be $\frac{p L}{\phi}$.

Period accounting profits for the representative firm, matched with a worker, are thus:

$$
\Pi=(p-w) L-r K,
$$

where $w$ is the wage rate, and $r$ is the capital costs. In contrast to the standard DMP model, where $p$ follows a Markov process, we assume that the interest rate $r$ follows a Markov process $G\left(r^{\prime}, r\right)=\operatorname{Pr}\left(r_{t+1} \leq r \mid r_{t}=r\right)$. We take the productivity rate, $p$, as given $4^{4}$

Firms choose how many vacancies to post each period at cost $c$ per vacancy, which is allowed to vary with the interest rate.

\subsection{Matching}

Vacant jobs $(v)$ and unemployed workers $(u)$ are randomly matched according to a constant returns to scale matching technology. The matching function, $M(u, v)$, represents the number of matches in a period. We follow HM in picking our matching function:

$$
M(u, v)=\frac{u v}{\left(u^{l}+v^{l}\right)^{\frac{1}{l}}},
$$

where $l$ is a parameter that controls the matching technology. This function form has the desirable properties that the job finding rate for a worker, and the job filling rate for a firm, are always being between 0 and 1 . The job finding rate for a worker, $\lambda^{w}=\frac{M(u, v)}{u}$. Similarly, the job filling rate for the firm is $\lambda^{f}=\frac{M(u, v)}{v}$. Note that the job filling rate depends on market tightness. Denote $q(\theta)=\lambda_{\theta}^{f}$.

A match separates with exogenous periodic probability $\sigma$ that is independent of the state for now, but in Section 3.5 will become a function of the interest rate spread. The evolution of the number of unemployed workers, $u$, can be described by

$$
u^{\prime}=\left(1-\lambda^{w}\right) u+\sigma(1-u)
$$

where a next period variable is denoted by a prime $\left(^{\prime}\right)$.

\footnotetext{
${ }^{4}$ In future work, we can include productivity shocks and study the interaction between the mechanisms in the rest of the DMP literature and those proposed in this paper.
} 


\section{Equilibrium}

\subsection{Worker Value Function}

In this subsection we specify the worker's optimization problem and optimal policy functions.

Let $W$ denote the value function of an employed worker. Let $U$ denote the value function of an unemployed worker. Workers move between employment and unemployment according to the (endogenous) job finding rate $\left(\lambda^{w}\right)$, and the (exogenous) job separation rate $(\sigma)$. Workers take both probabilities parametrically. Denote market tightness by $\theta=\frac{v}{u}$.

The worker's wage, which is determined by Nash equilibrium as explained below, is $w$. Unemployed workers receive a utility value of $b$. This represents the value of leisure and homeproduction.

$$
\begin{aligned}
W_{s} & =w_{s}+\beta\left\{(1-\sigma) E_{s} W_{s^{\prime}}+\sigma E_{s} U_{s^{\prime}}\right\} \\
U_{s} & =b+\beta\left\{\theta_{s} q\left(\theta_{s}\right) E_{s} W_{s^{\prime}}+\left(1-\theta_{s} q\left(\theta_{s}\right)\right) E_{s} U_{s^{\prime}}\right\}
\end{aligned}
$$

\subsection{Firm Value Function}

Firms create jobs, rent capital from banks, and produce. The firm maximizes the discounted present value of the profits. To create a job, a firm first posts a vacancy. There is a flow cost of posting a vacancy, denoted by $c_{s}$, which is allowed to depend on the interest rate. The value of posting a vacancy, $V$, is

$$
V_{s}=-c_{s}+\beta\left\{q\left(\theta_{s}\right) E_{s} J_{s^{\prime}}+\left(1-q\left(\theta_{s}\right)\right) E_{s} V_{s^{\prime}}\right\},
$$

The firm discounts the future at the rate $\beta . J_{s}$ is the value of a job filled by a worker. The value of a filled job, given the wage $w$, is

$$
J_{s}=p-w_{s}-r_{s} k+\beta\left\{(1-\sigma) E_{s} J_{s^{\prime}}+\sigma_{s} E_{s} V_{s^{\prime}}\right\}
$$




\subsection{Wage determination}

The wage is determined by generalized Nash bargaining. We assume that firms cannot commit to wages, so that wages are set period by period. The Nash bargaining solution solves the problem:

$$
\max _{w_{s}}\left(W_{s}-U_{s}\right)^{\gamma}\left(J_{s}-V_{s}\right)^{1-\gamma},
$$

where $\gamma \in(0,1)$ represents the bargaining power of the worker.

\subsection{Solution}

The state of the economy is $r_{s}$. Define the total surplus as $S_{s}=\left(J_{s}-V_{s}\right)+\left(W_{s}-U_{s}\right)$. With $V_{s}=0 \forall s \in \mathbf{S}$ the surplus is equal to:

$$
S_{s}=p-b-r_{s} k+\beta\left\{\left((1-\sigma) E_{s} S_{s^{\prime}}-\theta q(\theta) E_{s}\left(W_{s^{\prime}}-U_{s^{\prime}}\right)\right)\right\}
$$

From Nash bargaining we get that:

$$
\frac{W_{s}-U_{s}}{\gamma}=S_{s}=\frac{J_{s}}{1-\gamma}
$$

Now use the free-entry condition, $\forall s$, using Equation 9, the number of vacancies posted in a given state, $v_{s}$, is picked in order that market tightness, $\theta$, satisfies:

$$
E_{s} S_{s^{\prime}}=\frac{c_{s}}{(1-\gamma) \beta q\left(\theta_{s}\right)}
$$

Using the condition from Equation 14 in Equation 12, we arrive

$$
S_{s}=p-b-r_{s} k+\beta\left\{\left(1-\sigma_{s}\right) E_{s} S_{s^{\prime}}-\frac{\theta \gamma}{1-\gamma} \frac{c_{s}}{\beta}\right\}
$$

The number of variables is then two times the number of states $\left\{\theta_{s}, S_{s}\right\}_{s \in \mathbf{S}}$ and there is an equivalent number of equations. The equilibrium conditions must therefore solve Equations 14 and 15 , that is, $\theta_{s}$ and $S_{s}$ must solve these equations. 


\subsection{Full Model: Adding Default}

From the interest rate spread we infer a default rate among firms in the economy $[5$ We allow default to affect the model in two ways:

1. When the spread rises, there is an increase in bankruptcy. When a bankruptcy occurs, the firm loses ownership over the profit flow from the match. The effective separation rate from the match for the firm will thus be $\psi_{s}$.

2. Some bankruptcies will result in layoffs, or separations for the worker, while others simply allow the match to continue under different ownership. Separations will thus become state dependant as well with $\sigma_{s}$.

We now rewrite Equations 6, 7, and 10 ,

For Equations 6 and 7, the only difference is that the separation rate now is state dependant. These equations, respectively, become:

$$
u^{\prime}=\left(1-\lambda^{w}\right) u+\sigma_{s}(1-u)
$$

and

$$
W_{s}=w_{s}+\beta\left\{\left(1-\sigma_{s}\right) E_{s} W_{s^{\prime}}+\sigma_{s} E_{s} U_{s^{\prime}}\right\} .
$$

For Equation 10, the only difference is that the separation rate for the firm is now the combined probability of an exogenous, non state-dependant separation, plus the probability of a bankruptcy. We call this joint probability $\psi_{s}$. Equation 10 thus becomes:

$$
J_{s}=p-w_{s}-r_{s} k+\beta\left\{\left(1-\psi_{s}\right) E_{s} J_{s^{\prime}}+\psi_{s} E_{s} V_{s^{\prime}}\right\}
$$

For our equilibrium conditions to hold, we must therefore rewrite 15 . This equation becomes:

$$
S_{s}=p-b-r_{s} k+\beta\left\{\left(1-\psi_{s}\right) E_{s} S_{s^{\prime}}-\frac{\left(\theta q(\theta)-\psi_{s}+\sigma_{s}\right) \gamma}{(1-\gamma) q(\theta)} \frac{c_{s}}{\beta}\right\}
$$

\footnotetext{
${ }^{5}$ See the calibration section for specifications on how we infer default rates and separation rates from the spread.
} 


\section{Mechanisms}

There are four mechanisms in the model presented for the relationship between interest rates and interest rate spread on one hand, and unemployment on the other. In this section, we describe the channels.

1. When the interest rate rises, there is less surplus available to split between the firm and the worker. The decline in surplus reduces the incentives for firms to post vacancies, resulting in a rise in unemployment. We call this channel the direct profit channel.

2. Vacancy costs in this model are low, at $58.4 \%$ of weekly productivity. ${ }^{6}$ The capital component of these costs rise proportionally with the interest rate. The idea is that if a firm needs working capital in order to have a position available, then when interest rates rise, this component of vacancy costs rise as well. Firms thus post fewer vacancies, and unemployment rises. We call this the direct vacancy channel.

3. The bankruptcy rate determines how long the owner of the firm expects to remain claimant on the profits generated by the match. When this rate increases, the expected profits the owner receives decreases. As a result, the incentive to post vacancies declines, thus increasing unemployment. We call this channel the indirect bankruptcy channel.

4. When firms enter bankruptcy, they may downsize or shut down entirely. This results in an immediate increase in the separations between workers and firms, causing an increase in unemployment. We call this channel the direct bankruptcy channel.

\section{Quantitative Exercise}

We will do two exercises. The first is to calibrate the partial model, following the strategy outlined by HM. As mentioned in the Introduction, we begin by quantifying the direct vacancy cost mechanism. We do so by setting $k=0$. As described below, we will set some parameters based on a priori information, and some based on matching model moments to data moments. Success will be showing that fluctuations in the interest rate/spread can replicate the cyclical properties of unemployment, vacancies, and market tightness in the US data. The second exercise will be simulating the time series dynamics of the unemployment rate based on the realized experience of the interest rate spread.

\footnotetext{
${ }^{6}$ This number is taken from HM.
} 


\subsection{Calibration- Partial Model}

We follow HM in our calibration strategy, but not all the numbers used. We begin by setting a week as a time period in order to account for aggregation bias.

Following the procedure outlined in HM to estimate a weekly AR(1) process of the real BAA interest rate. We find the persistence and unconditional standard deviation to be 0.9863 and 0.0029 , respectively. Details can be found in Appendix A.

Continuing with HM, the mean weekly separation rate in the US, after accounting for time aggregation, is 0.0081 . The discount rate is set to $0.99^{\frac{1}{12}}$, representing a quarterly discount rate of .99. The average vacancy cost, $c$, is 0.584 , which is composed of an average capital cost of 0.474 and a fixed labor cost of 0.11 . The capital component of this cost varies with the interest rate, with the cost rising proportionally with the interest rate.

We now turn to the remaining parameters, $b, l$, and $\gamma$, which are picked to match model moments. Continuing in the spirit of HM, we target the average job finding rate, 0.139 , the average market tightness, $\frac{v}{u}=0.634$, and the elasticity of wages with respect to the interest rate, -0.0135 . Note that HM match the job finding rate and average market tightness, but as a third moment they match the elasticity of wages with respect to productivity. Given that we use the interest rate as our exogenous shock, rather than productivity, our strategy is the natural transformation of HM's strategy.

Picking $b, l$, and $\gamma$ to minimize the distance between model and data moments, we arrive at the following parameters. We find the flow utility of an unemployed worker, $b$, to be 0.56 . The bargaining weight of the worker, $\gamma$, is 0.52 . The matching efficiency parameter, $l$, is 0.402 . In Table 1 below we report the model and data moments associated with our calibration.

\begin{tabular}{lcl}
\multicolumn{3}{c}{ TABle 1: Moments: DatA And Model } \\
\hline \hline \multicolumn{1}{c}{ Moment } & Data & \multicolumn{1}{c}{ Model } \\
Job Finding Rate & 0.139 & 0.139 \\
Market Tightness & 0.634 & 0.634 \\
Elasticity of W wrt R & -0.014 & -0.030 \\
\hline \hline
\end{tabular}

We believe that the model has succeeded in matching the data moments quite well. The job finding rate and market tightness are perfect. The elasticity of wages with respect to the interest rate is slightly off in the model, but of the same order of magnitude. Both the data and model are quite close to 0 . Our calibration is outlined in the below table 
TABle 2: Parameter VAlues

\begin{tabular}{llll}
\hline \hline Param & \multicolumn{1}{c}{ Meaning } & \multicolumn{1}{c}{ Value } & \multicolumn{1}{c}{ Identification } \\
$\sigma$ & Job separation & 0.0081 & Exog (HM) \\
$\beta$ & Discount rate & $0.99^{\frac{1}{12}}$ & Exog (HM) \\
$c$ & Vacancy Costs & 0.5840 & Exog (HM) \\
$\rho_{r}$ & Wkly pers. int. rate & 0.9863 & Authors Calculation \\
$\sigma_{r}$ & Std. Dev. int. rate. & 0.0029 & Authors Calculation \\
$\gamma$ & Worker Bargaining Weight & 0.52 & Matching Data Moments \\
$b$ & Unemployment Flow Utility & 0.56 & Matching Data Moments \\
$l$ & Matching Param & 0.402 & Matching Data Moments \\
\hline \hline
\end{tabular}

Notice that the worker bargaining weight, $\gamma$, is less than the value obtained by Shimer, 0.72, while greater than that of HM, 0.052. Similarly, our value of worker's flow utility is higher than Shimer's, based purely on unemplyoment benefits, and lower than that of HM, which is close to model's wage rate and labor productivity. For our model, the value works out to be $58 \%$ of the average wage. Our matching function parameter is quite similar to HM, 0.407, and absent from Shimer's model.

\subsection{Calibration- Full Model}

In the full model, there are state dependant separations, $\sigma_{s}$, and state dependant firm owner lose their claim to the future profits generated by the match. The separation rate between the firm and worker is now $\sigma_{s}=\bar{\sigma}+(1-\bar{\sigma}) \eta_{2} \eta_{1} f\left(\Delta_{r}\right)$, where $\bar{\sigma}$ is an invariant probability of a match dissolving, and $\eta_{2} \eta_{1} f\left(\Delta_{r}\right)$ is the rate of match dissolution that results from a given interest rate spread, $\Delta_{r}$. Furthermore, there is a rate at which firm owners lose their claim to match profits, $\psi_{s}$. In our model, $\psi_{s}=\bar{\sigma}+(1-\bar{\sigma}) \eta_{1} f\left(\Delta_{r}\right)$. We now describe $f\left(\Delta_{r}\right), \eta_{1}$, and $\eta_{2}$.

$f\left(\Delta_{r}\right)$ is the bankruptcy rate in the economy implied by the interest rate spread, under the naive assumption that the spread is entirely due to bankruptcy. That is, $f\left(\Delta_{r}\right)=\frac{r_{e}-r_{f}}{1+r_{e}}$, where $r_{e}$ is the real interest rate faced by firms, and $r_{f}$ is the risk free rate. The implicit assumption here is that the recovery rate for firms that go into default is zero. Given a level of the interest rate spread, this implies a lower bound on the inferred default rate, making it a conservative assumption.

Despite our conservative estimate of the default rate due to a zero recovery rate, it is not reasonable to assume that all the fluctuations in the spread are due to changing bankruptcy rates. We add the parameter $\eta_{1}$ to capture the pass-through rate from spread to bankruptcy. We also want to 
capture the notion that some bankruptcies result in separations between worker and firm, but not all. That is, some firms continue to operate after bankruptcy, with their owners simply no longer claiming the flow profits. To capture the fraction of bankruptcies that result in a separation, we add $\eta_{2}$.

We need to make the following three changes to our calibration strategy.

- Separations are state dependant. We must therefore pick a constant separation rate in order match the mean separations in the US Data. That is, the mean separation rate of 0.0081 from the partial model is now a calibration target for the parameter $\bar{\sigma}$.

- We add time series data on vacancies, and it's correlation with the interest rate spread, as a target for our model. This informs on the indirect bankruptcy mechanism in our model. That is, if the spread results in more bankruptcies, and thus a higher rate of firm owners losing their future claims to profits, then firm owners will post fewer vacancies. Targeting the correlation between vacancies and the interest rate spread thus allows us to identify how much of the spread passes through to bankruptcy rates, as captured in parameter $\eta_{1}$.

- We target the correlation between the interest rate spread and separations. In our model, the spread results in a certain bankruptcy rate, of which $\eta_{2}$ result in a separation between worker and firm. Targeting this time series correlation thus allows us to identify $\eta_{2}$, and thus the direct bankruptcy mechanism.

\section{Results}

In this section, we describe the cyclical volatility of unemployment, vacancies, and market tightness as they relate to interest rate shocks. Similar to HM and Shimer, we report below a Table on the US time series data regarding these series, their autocorrelations, standard deviations, and correlations. 
TABle 4: QuARTERly Summary Statistics FrOM U.S. DATA, 1951:1 TO 2004:4

\begin{tabular}{lcccc}
\hline \hline & $u$ & $v$ & $v / u$ & $r$ \\
Std Dev & 0.125 & 0.139 & 0.259 & 0.162 \\
Quarterly Autocorrelation & 0.870 & 0.904 & 0.896 & 0.733 \\
Correlation $u$ & 1 & -0.917 & -0.977 & 0.269 \\
Correlation $v$ & - & 1 & 0.982 & -0.388 \\
Correlation $\frac{v}{u}$ & - & - & 1 & -0.343 \\
Correlation $r$ & - & - & - & 1 \\
\hline \hline
\end{tabular}

\subsection{The Partial Model, Calibrated}

We report how our calibrated partial model performs in matching these moments. It should be emphasized that these moments are not targeted, but rather a result of the calibration strategy described above in a DMP model with interest rate shocks.

The model moments line up quite well with the business cycle properties of the US data.

TABle 5: QuARTERly Summary Statistics From the CAlibRated Model

\begin{tabular}{llllc}
\hline \hline & $u$ & \multicolumn{1}{c}{$v$} & $v / u$ & $r$ \\
Std Dev & 0.077 & 0.092 & 0.159 & 0.168 \\
Quarterly Autocorrelation & 0.807 & 0.578 & 0.737 & 0.740 \\
Correlation $u$ & 1 & -0.764 & -0.928 & 0.927 \\
Correlation $v$ & - & 1 & 0.950 & -0.946 \\
Correlation $\frac{v}{u}$ & - & - & 1 & -0.998 \\
Correlation $r$ & - & - & - & 1 \\
\hline \hline
\end{tabular}

The results indicate that the model is able to replicate a large portion of US business cycle properties. The volatility of unemployment, vacancies, and market tightness are all about $60 \%$ of that observed in the data. The persistence of unemployment is quite close to it's empirical counterpart, while that of vacancies and market tightness are somewhat low. It should be noted that these two moments are off by a comparable amount as HM. Similarly, the correlation between unemployment and vacancies is similar in our model to HM, and somewhat low relative to the data. The correlation between market tightness and unemployment and vacancies are both quite close to the data. The magnitudes of the correlation between the interest rate and other variables is high, but this should be expected as the interest rate is currently the only shock. These correlations may well decrease in the full model. 


\subsection{Shimer's Calibration}

What if we followed the calibration strategy outlined in Shimer rather than HM? Shimer sets the flow utility of the unemployed worker to be $b=.4$. He sets the workers' bargaining power $\gamma=.72$. As Shimer does not have the same matching function as we do, we maintain $l=0.402$.

The model still replicates a large portion of US business cycle properties, as shown in Table 6. That is, the model replicates a large portion of the business cycle properties of the US data with both calibration strategies. We consider this to be strong evidence that the DMP model using interest rate shocks, rather than productivity shocks, is quite effective at explaining the US business cycle.

TABle 6: QuARTERly SumMARY StATISTICS FROM THE SHIMER CALIBRATION

\begin{tabular}{llllc}
\hline \hline & $u$ & $v$ & $v / u$ & $r$ \\
Std Dev & 0.082 & 0.094 & 0.160 & 0.168 \\
Quarterly Autocorrelation & 0.828 & 0.542 & 0.737 & 0.740 \\
Correlation $u$ & 1 & -0.665 & -0.899 & 0.899 \\
Correlation $v$ & - & 1 & 0.925 & -0.920 \\
Correlation $\frac{v}{u}$ & - & - & 1 & -0.997 \\
Correlation $r$ & - & - & - & 1 \\
\hline \hline
\end{tabular}

Notice that the results do not change in any meaningful way. This is due to the fact the we are considering the direct vacancy mechanism. The Shimer calibration versus the HM calibration do not differ with respect to how important this channel should be. This will change when we add the direct profit channel, which is similar in spirit to the point of disagreement between Shimer and HM. However, these results show that as a baseline, simply the direct vacancy channel can explain approximate $60 \%$ of the data. We will next turn to quantifying the remaining three mechanisms.

\subsection{Adding the Direct Profit Mechanism- preliminary and incomplete}

In this subsection we add the Direct Profit Mechanism. We follow HM in picking the value for $k=\frac{1}{3} \frac{(1-u)}{r}: 7$ We call these results presented here to be preliminary and incomplete due to the current difficulty in matching the elasticity of wages with respect to the interest rate.

\footnotetext{
${ }^{7}$ See their paper for details on this calculation.
} 
TABle 1: Moments: Data And Model

\begin{tabular}{lcl}
\hline \multicolumn{1}{c}{ Moment } & Data & \multicolumn{1}{c}{ Model } \\
Job Finding Rate & 0.139 & 0.139 \\
Market Tightness & 0.634 & 0.634 \\
Elasticity of W wrt R & -0.014 & -0.467 \\
\hline \hline
\end{tabular}

The corresponding parameter values are $\gamma=0.46, b=0.65$, and $l=0.405$. These parameter values are not substantially different than reported above. The results are stronger, indicating that the direct profit mechanism is as strong as the direct vacancy mechanism. These two mechanisms combined make the overall model able to replicate the US business cycle statistics quite well

\begin{tabular}{|c|c|c|c|c|}
\hline & $u$ & $v$ & $v / u$ & $r$ \\
\hline Std Dev & 0.133 & 0.168 & 0.279 & 0.121 \\
\hline Quarterly Autocorrelation & 0.751 & 0.448 & 0.650 & 0.656 \\
\hline Correlation $u$ & 1 & -0.703 & -0.903 & 0.902 \\
\hline Correlation $v$ & - & 1 & 0.940 & -0.932 \\
\hline Correlation $\frac{v}{u}$ & - & - & 1 & -0.995 \\
\hline Correlation $r$ & - & - & - & 1 \\
\hline
\end{tabular}

We now use the Shimer calibration as above, and report the results in Table 8.

\begin{tabular}{|c|c|c|c|c|}
\hline & $u$ & $v$ & $v / u$ & $r$ \\
\hline Std Dev & 0.108 & 0.134 & 0.217 & 0.121 \\
\hline Quarterly Autocorrelation & 0.779 & 0.419 & 0.650 & 0.656 \\
\hline Correlation $u$ & 1 & -0.605 & -0.870 & 0.872 \\
\hline Correlation $v$ & - & 1 & 0.918 & -0.912 \\
\hline Correlation $\frac{v}{u}$ & - & - & 1 & -0.997 \\
\hline Correlation $r$ & - & - & - & 1 \\
\hline
\end{tabular}

We make two observations about these results. First, that the under the Shimer calibration, the results are indeed stronger with the direct profit channel than without it. For instance, the standard deviation of unemployment rises from 0.082 to 0.108 , a $31 \%$ increase. This indicates that this channel has quantitative influence even under Shimer's calibration. This is signifcant as the 
equivalent of the direct profit channel in Shimer's paper yields virtually no volatility. Here it is important.

The second point to notice is that the difference in volatility with and without the direct profit channel is larger under the HM calibration strategy than under the Shimer calibration. That is, the HM calibration strategy yields a stronger influence for the direct profit channel. This should not be surprising, as this is precisely the point of contention between those two calibrations of the DMP model.

\subsection{The Full Model}

To be completed in accordance with the strategy described above.

\section{Conclusion}

Following the Great Recession, there has been renewed interest in how and to what extent financial conditions affect unemployment. The correction between the interest rate spread and unemployment captures this notion in a concise manner. We offered two contributions based on this observation. First, we have presented four mechanisms by which financial conditions can affect unemployment in a DMP model. Second, we offer a methodology for quantifying these channels, and show preliminary results suggesting that financial conditions are indeed important to consider when studying unemployment dynamics. As noted in the introduction, we are not trying to solve the so-called 'Shimer Puzzle'. Rather, we are introducing a new set of shocks related to financial conditions and quantifying their associated economic channels.

To this end, we follow the DMP literature in disciplining our model and evaluating quantitative importance. We use both the HM strategy, but not parameter values, as well as Shimer parameter values. We do not target the data we are looking to explain. The model is robustly able to explain a significant portion of business cycle level volatility, with just the direct vacancy channel, and preliminary results indicate that including the direct profit channel allows the model to explain most of the US data with reasonable parameter values. Continuing work will finish quantifying the remaining mechanisms. 


\section{A Data Appendix}

Data details go here. 


\section{References}

Christiano, L. J., M. S. Eichenbaum, and M. Trabandt (2013): “Unemployment and business cycles," International Finance Discussion Papers 1089, Board of Governors of the Federal Reserve System (U.S.).

Diamond, P. A. (1982): “Aggregate Demand Management in Search Equilibrium,” Journal of Political Economy, 90(5), 881-94.

Hagedorn, M., F. Karahan, I. Manovskit, and K. Mitman (2013): "Unemployment benefits and unemployment in the Great Recession: the role of macro effects," Staff Reports 646, Federal Reserve Bank of New York.

Hagedorn, M., And I. MAnOvsKiI (2008): “The Cyclical Behavior of Equilibrium Unemployment and Vacancies Revisited," American Economic Review, 98(4), 1692-1706.

HALl, R. E. (2014): “High Discounts and High Unemployment,” NBER Working Papers 19871, National Bureau of Economic Research, Inc.

Hall, R. E., And P. R. Milgrom (2008): "The Limited Influence of Unemployment on the Wage Bargain," American Economic Review, 98(4), 1653-74.

Mitman, K., And S. Rabinovich (2013): "Do Changes in Unemployment Insurance Explainthe Emergence of Jobless Recoveries?," Discussion paper.

Mortensen, D. T. (1982): "Property Rights and Efficiency in Mating, Racing, and Related Games," American Economic Review, 72(5), 968-79.

Petrosky-Nadeau, N., And L. Zhang (2013): “Unemployment Crises,” GSIA Working Papers 2013-E5, Carnegie Mellon University, Tepper School of Business.

PISSARIDES, C. A. (1985): "Short-run Equilibrium Dynamics of Unemployment Vacancies, and Real Wages," American Economic Review, 75(4), 676-90.

SHIMER, R. (2005): “The Cyclical Behavior of Equilibrium Unemployment and Vacancies," American Economic Review, 95, 25-49.

WASMER, E., AND P. WeIL (2004): “The Macroeconomics of Labor and Credit Market Imperfections," American Economic Review, 94(4), 944-963. 
YAshiv, E. (2013): “Capital Values, Job Valuesand the Joint Behavior of Hiring andInvestment," Working paper. 